\title{
LEARNing management 1.0: UMA PROPOSTA LÚDICA PARA A APLICAÇÃO DA ANÁLISE ESTRATÉGICA
}

\author{
Alice Beatriz Pimenta Oliveira de Sá (Instituto Federal do Rio Grande do Norte) \\ alice.beatriz.pimentta@gmail.com \\ Giselly de Medeiros Santos da Silva (Instituto Federal do Rio Grande do Norte) \\ gisellymssilva2@gmail.com \\ Maria Eduarda Correia Pedrosa (Instituto Federal do Rio Grande do Norte) \\ eduardapedrosamecp@gmail.com \\ Marcus Vinicius Dantas de Assunção (Instituto Federal do Rio Grande do Norte) \\ marcus.assuncao@ifrn.edu.br
}

\section{Resumo}

Os jogos simuladores dispõem de atributos que proporcionam uma melhor qualificação devido à possibilidade de encenar um contexto real e aplicar teorias de forma prática e segura. Tendo ciência dos benefícios da aplicabilidade dos jogos simuladores na conjuntura educacional, o presente artigo tem com objetivo propor o jogo acadêmico Learning Management, que apresenta conhecimentos sobre as disciplinas de Gestão Empresarial e Estratégia e Gestão de Operações, dispondo-se aos estudantes da área de Engenharia de Produção e Logística. O jogo em questão se caracteriza como de tabuleiro e cartas e sua finalidade é instigar o pensamento estratégico de cada jogador perante as possíveis penalidades com o propósito de finalizar o trajeto no menor tempo possível.

Palavras-Chaves: Jogos em Logística, Jogos Acadêmicos, Gestão Empresarial e Estratégia, Gestão de Operações, Estratégia.

\section{Introdução}

É cada vez mais notória a necessidade requisitada pela sociedade a respeito da qualificação profissional e educacional. Diante à dinamização do cenário atual, torna-se cada vez mais comum a busca por métodos que auxiliem na aprendizagem e conecte de forma agiu e fácil o binómio teoria x prática. A utilização de meios didáticos para fins educacionais surge como um meio transformador frente aos paradigmas tradicionais, tornando a procura por conhecimento, um exercício mais flexível e estimulador.

Os procedimentos reacionários de ensino se mostram, na conjuntura contemporânea, insuficientes para garantir o estudo eficaz do aluno que se releva a fim de sanar as 
exiguidades existentes. Quando posto em prática, esses processos podem, na maioria das vezes, torna-se um fator desestimulador ao praticante, uma vez que não se consegue alcançar os objetivos com êxito o que os fazem sentirem, por vezes, cansados de buscar formas de atingir respostas satisfatórias às suas indagações.

Um método presente em nosso dia a dia desde os tempos remotos, caracterizado pela eficiente habilidade instrucional, são os jogos. Além de orientar, o jogo possui competência de assimilação e construção de novos conhecimentos e exercita a capacidade mental, funcional e intelectual do jogador. Barbosa (1998) afirma que os jogos educacionais podem se caracterizar como um elemento catalisador, capaz de contribuir para o "processo de resgate do interesse do aprendiz, na tentativa de melhorar sua vinculação afetiva com as situações de aprendizagem".

Diante da carência de ferramentas de ensino aprendizagem que cativem o praticante na busca incessante pela aptidão exigida do mercado tecnocrático, o presente artigo tem como objetivo apresentar um jogo acadêmico desenvolvido para exortar questionamentos das disciplinas empresariais de Gestão de operações, Logística e Gestão empresarial e estratégia.

\section{Referencial teórico}

\subsection{Logística}

Seja qual for o segmento de uma organização, é de total importância que exista uma gestão que se encarregue na tomada de decisões, organizações das atividades e processos, aplicação de recursos necessários para o desenvolvimento continuo da empresa e que estabeleça um vínculo harmônico entre produtores e consumidores, intitulamos que, esse controle de fluxos desde a produção até o cliente final chama-se logística (SILVA; PEDROSA; SÁ; ASSUNÇÃO, 2019).

O Cuncil of Logistics Management, citado por Laugeni apud et al (2015), definiu a logística como o efetivo relacionado ao fluco de armazenagem de matéria-prima, material em processo e produto acabdo, assim como também o fluxo de informações, do ponto de origem ao de consumo, visando atender às exigências do cliente. $\mathrm{O}$ autor relaciona ainda a Logística com áreas da produção e marketing de empresa, como ilustrado na Figura 1. 


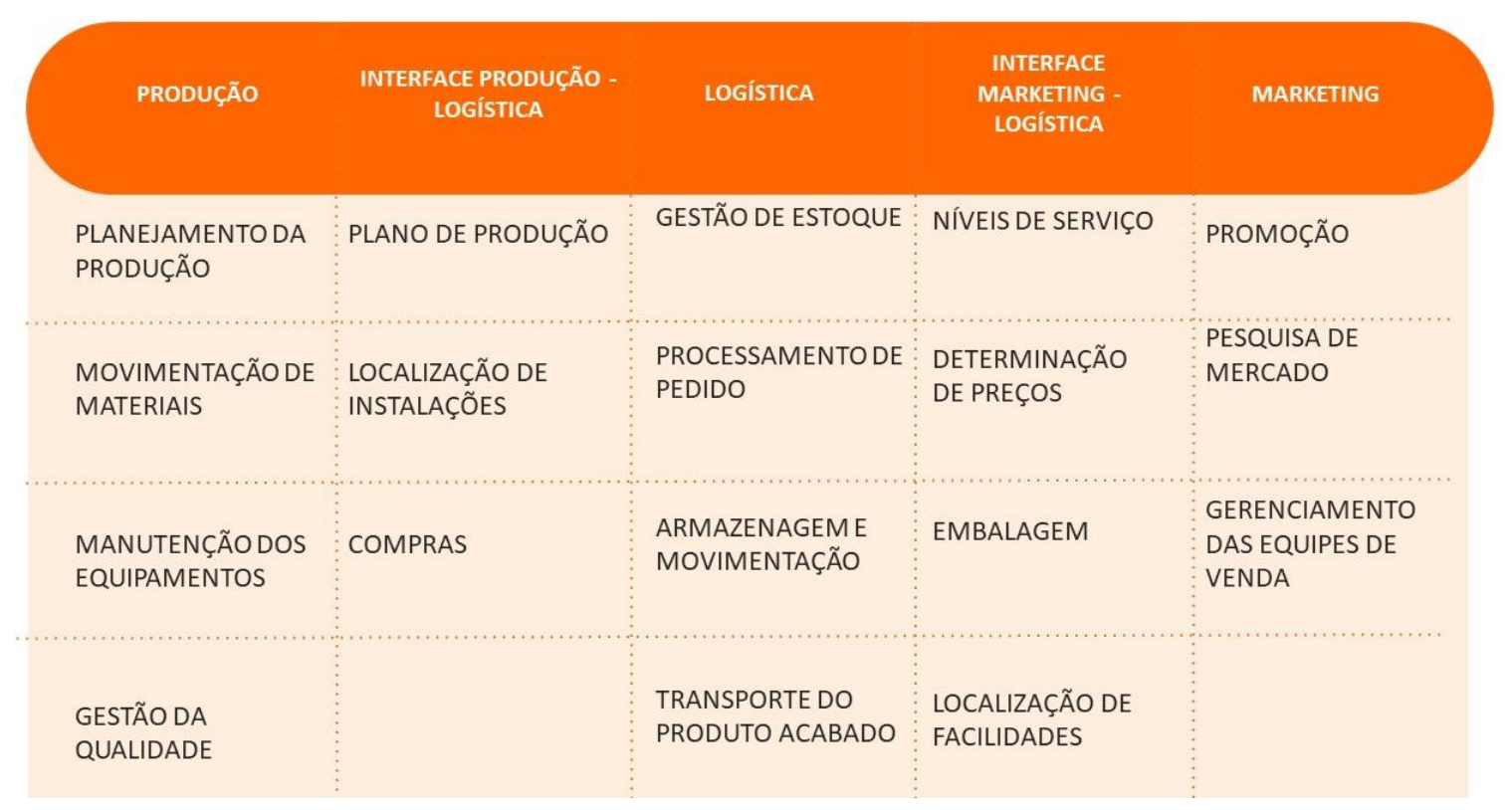

Fonte: Adaptado de BALLOU, R. H. Business logistics management. Englewood Cliffs, NJ: Prentice Hallm, 1999

Laugeni apud et al (2015) elenca algumas das decisões logísticas envolvidas no processo estratégico, tático e operacional, estas estão representadas na Figura 2.

Figura 2 - Decisões logísticas

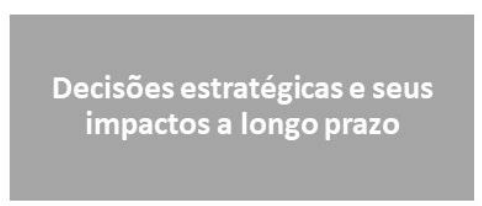

- Quantidade e localização de facilidades;

- Quantidade e função dos centros de distribuição, depósito e armazéns;

- Tipo de equipamento de movimentação e de produção;

- Determinação dos estoques (tipos e localização na supply chain).

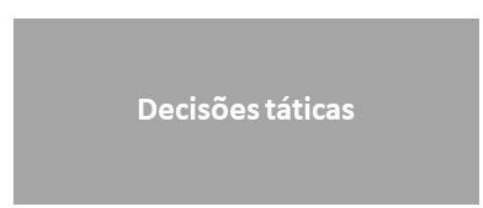

- Meios de transporte;

- Níveis de estoques;

- Medidas de desempenhos;

- Roteiros.

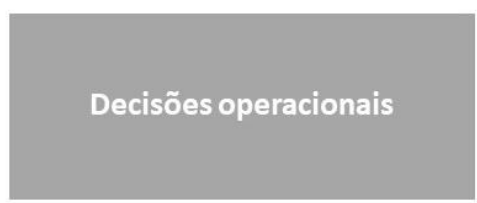

- Programa diário de produção;

- Programa diário de embarques;

- Roteiros diários;

- Alocações de pessoal.

Fonte: LAUGENI, Fernando P.; MARTINS, Petrônio G. 3. Ed. - São Paulo: Saraiva, 2015. logística empresarial. $4^{\mathrm{a}}$ ed. Porto Alegre: Bookmann, 2001

\subsection{Gestão empresarial e estratégia}


De acordo com a Council of Supply Chain Management Professionals (CSCMP, 2013), a gestão empresarial é uma área de grande proporção, no sentido organizacional, responsável pela administração e gerenciamento de serviços, materiais e informações de uma empresa. Utilizando, para isso, meios econômicos, práticos e seguros, a fim de atingir a satisfação do cliente através de suas atividades. A estratégia é a determinação dos objetivos de longo prazo, das políticas e ações adequadas para os atingir e a correspondente a pretensão de recursos, ou seja, a estratégia compreende a definição dos objetivos e dos meios, conforme Chandler (1962); Learned, Christensen, Andrews e Guth (1965); Ansoff (1965); Katz (1970); Andrews (1971); Steiner e Miner (1977), Hax e Majluf (1988); Quinn (1980) referenciados por Nicolau, I. (2001).

Em relação à estratégia empresarial, dispõe-se do balanced scorecard. Segundo Kaplan (1997), é uma ferramenta que auxilia as organizações a consolidar a estratégia em objetivos operacionais que direcionam comportamentos e funcionalidades. É utilizado por várias empresas como a principal ferramenta organizacional para importantes procedimentos gerenciais, tais como estabelecimento de metas individuais e de equipe, remuneração, alocação de recursos, planejamento e orçamento, feedback e aprendizado estratégicos. Deixa claro que as medidas financeiras e não-financeiras devem fazer parte do sistema de informações para funcionários de todos os níveis da organização, pois derivam de um processo hierárquico.

Também vinculado a isso atribui-se a análise SWOT (Strengths, Weaknesses, Oppotunities e Threats), que na sua tradução é força fraqueza, oportunidade e ameaça, é uma técnica utilizada para a gestão e o planejamento das empresas, seja ela de pequeno ou grande porte, consoante Fernandes (2015).

\subsection{Gestão de operações}

De acordo com Maia (2008), as práticas de gestão constituem elementos que dinamizam o cotidiano de organizações. As ações dos dirigentes voltam-se para diferentes setores estando diante de especificidades das decisões face ao tipo de tarefa e aos agentes organizacionais. Lisboa e Gomes (2006) revela que o objetivo fundamental da gestão de operações é garantir a transformação eficaz de recursos (inputs) em produtos ou serviços (outputs). Por esse motivo, independentemente do tipo de organização, as decisões que devem ser tomadas nessa área são semelhantes e faz referência de como será a forma, de serviço ou produto, executado. 
A gestão de operações carregar consigo uma função primordial de guiar a empresa por caminhos que auxiliem na redução de custo e tempo. É a gerência responsável pelas questões de natureza estrutural e estratégica, nomeadamente aquelas que estão relacionadas com o produto/serviço, o seu processo de produção, o tipo de layout a utilizar, as especificidades do posto de trabalho, ou ainda a localização física das instalações (Lisboa e Gomes, 2006)

Relacionado a esse conhecimento, uma conduta vinculada ao planejamento que deve ter um grau de importância em toda a organização é saber como escolher e aplicar o melhor tipo de layout. A importância da distribuição física de uma empresa é reforçada pelas consequências em longo prazo das decisões e do custo de repensar a planta (Tortorella e Fogliatto, 2008). Consoante a isso, um layout inicial correto é fundamental para a efetividade e eficiência operacional de uma empresa (URBAN, 1989).

\subsection{Jogos em logística}

A capacitação do corpo gerencial nas áreas de gestão apresentam-se como uma necessidade, tanto no setor empresarial quanto na área acadêmica. Os meios de fornecer essa capacitação devem promover a absorção dos principais conceitos, bem como sua assimilação prática. A teoria pode ser transmitida através de cursos, que envolvem aulas expositivas, palestras, leituras e seminários (MIYASHITA et al, 2003). Há carência de recursos que auxiliam na assimilação da teoria com a prática no campo da logística empresarial, à vista disso, é um encargo que carece de mecanismos que requer uma certa elaboração planejada, como são o método do caso e os jogos de empresariais.

Wilhelm (1997) definiu os jogos de empresas como ferramentas que têm a mesma estrutura do jogo simulado, isto é, possuem regras claras e bem definidas, presença de espírito competitivo, possibilidade de identificar vencedores e perdedores, ludicidade, fascinação e tensão. Porém, o jogo simulado atua além disso, ele permite que os jogadores coloquem em prática suas habilidades técnicas relacionadas à área empresarial, adiantando a prática profissional a partir de um meio lúdico, realizando sequências de interações proporcionadas pelo jogo simulado. Os jogos quando aplicados como instrumento de ensino aprendizagem apontam ter um significante potencial estratégico, que no contexto atual, torna-se essencial, em virtude da escassez de recursos educacionais imersos nesse cenário tecnocrático competitivo. A fácil adesão de conceitos técnicos somados à prática lúdica garante que a atividade renda tanto em amplitude de conhecimento, como em profundidade. 
Sintetizando as teses desenvolvidas por CARLSON; MISSHAUK, 1972; MARTINELLI, 1987; SAUAIA, 2006; VIEIRA FILHO, 2008; HONAISER; SAUAIA, 2008, nota-se que comparando o jogo com outros métodos de ensino, evidencia-se grandes vantagens: a efetivação da prática que não é empregada em outros métodos, como por podemos citar, as aulas expositivas e a leitura; a progressão de habilidades que não são adquiridas no desenvolvimento das metodologias tradicionais; facilidade na aplicação e um maior interesse prática por existir a dinamização na execução; aplicação de conceitos que só seriam utilizados posteriormente incorporado na rotina profissional.

\section{Metodologia}

A elaboração do jogo Learning Management 1.0 se deu em 4 etapas: (I) Pesquisa bibliográfica visando domínio na temática, (II) Definição da atividade logística ao qual o jogo será voltado, (III) Construção do contexto lúdico, definiçãa de metas e objetivos, (IV) Revisão geral da prática desenvolvida. A Figura 3 representa de maneira ilustrativa essas fases metodológicas da pesquisa.

Figura 3 - Etapas da Pesquisa

\section{Etapas da pesquisa}

Nesta etapa foi realizado um levantamento sobre os jogos logísticos já existentes e observou-se carência de jogos voltados para a área empresarial que aguçasse a performance estratégica dos jogadores.
Buscando ampliar as metodologias didáticas de ensino, foi desenvolvido um jogo de cunho acadêmico com o intuito de promover o pensamento estratégico perante as problemáticas ao decorrer do jogo assim como exercitar o conteúdo sobre Gestão empresarial e estratégia e Gestão de operações.

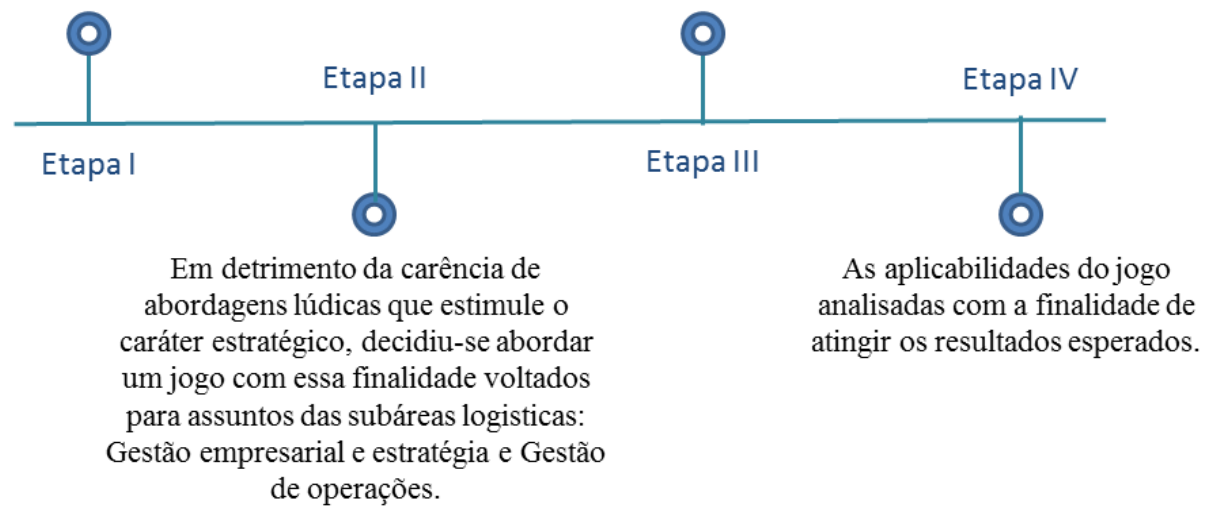


Para uma melhor efetivação da etapa III, no que tange à aplicação dos conteúdos referentes as disciplinas de Gestão Empresarial e Estratégia e Gestão de Operações, o jogo possuirá uma ferramenta que irá propor questionamentos com a função principal de aperfeiçoar os conhecimentos á respeitos das disciplinas mencionadas. E para nortear esse procedimento escolhemos os assuntos que serão trabalhados, apresentada de forma didática pela tabela 1

- Tabela 1 - Conteúdos trabalhados durante a prática do jogo

\section{Disciplina}

\section{Conteúdos trabalhados durante a prática}

\section{do jogo}

- Estratégia como plano, padrão, posição e perspectiva

- Análise do ambiente externo

- Análise do ambiente interno

- Gestão Estratégica

Gestão Empresarial e Estratégia

- Elaboração de planos de ação estratégia

- Implementação dos planos e estratégias

- Acompanhamento e alinhamento estratégico - Balanced Scorecard 
- O papel estratégico de operações e objetivos de desempenho (A função produção, Objetivos de desempenho, A importância relativa dos objetivos de desempenho)

- Estratégias de Localização (A

Gestão de Operações importância estratégica da localização, Fatores que afetam a decisão de localização, Métodos de avaliação das alternativas de localização)

- 4. Estratégia de arranjo físico (A importância estratégica das decisões

de layout, Tipos de layout)

Fonte: Autores (2020)

\section{Resultados e discussões}

O jogo foi elaborado perante as necessidades de práticas educacionais didáticas no setor logístico que instigue o planejamento de estratégias visando sanar as carências observadas na tomada de decisão e buscando a aplicação dos assuntos trabalhados na Gestão empresarial e estratégia e Gestão de operações. É um jogo de tabuleiro e cartas e recomenda-se sua prática em grupo. A Tabela 1 apresenta a descrição geral do jogo.

Tabela 2 - Descrição geral do jogo

Objetivo

Público alvo

Conhecimentos

Tipo

abordados

\begin{tabular}{cccc}
\hline Instigar a prática do & Estudantes na área de & Gestão empresarial e & Tabuleiro e \\
planejamento estratégico e & Engenharia de & estratégia, Gestão de & cartas \\
relembrar os conteúdos vistos & Produção e Logística & Operações & \\
nas disciplinas de Gestão & & & \\
\hline
\end{tabular}


empresarial e estratégia e

Gestão de Operações

Fonte: Autores (2020)

\subsection{Descrição do jogo}

Learning Management 1.0 é um jogo com foco educacional direcionado às áreas de Engenharia de Produção e Logística que possui objetivo de exercitar conceitos provenientes das disciplinas de Gestão Empresarial e Estratégia e Gestão de Estoque, como Layout e análise SWOT, além de instigar o planejamento estratégico visando melhorias nas tomadas de decisões que possivelmente virá a acontecer em um ambiente de trabalho. O jogo possui um tabuleiro e cartas com a intenção principal de promover a análise estratégica que resulte no término do jogo no menor tempo possível.

\subsection{O jogo suas pontuações e penalidades}

O jogo consiste em um tabuleiro (Figura 4) que possui 31 casas com o principal objetivo de chegar a última casa no menor tempo possível. Para iniciar o jogo é preciso que cada jogador ou grupo esteja com 1 dado avatar (Figura 5), que será responsável por mostrar onde cada jogador se encontra durante a prática.

Figura 4- Tabuleiro do jogo 


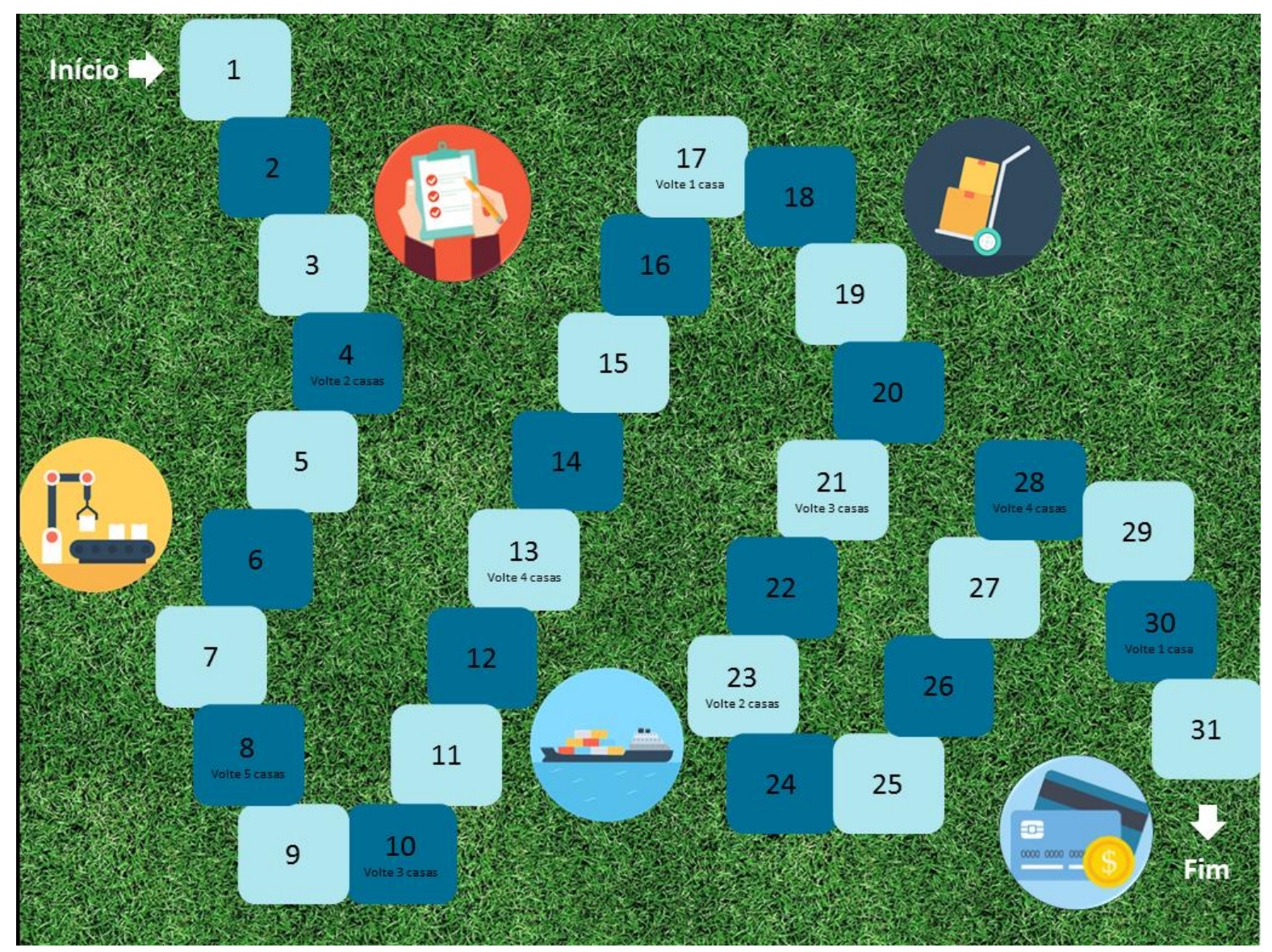

Fonte: Autores (2020)

Figura 5- Dados avatar

Dados avatar

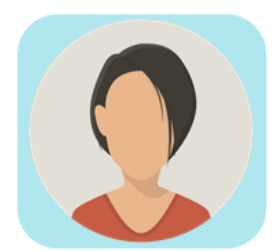

Avatar 1

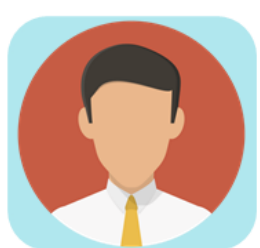

Avatar 2

Mesma configuração para todos os lados

Fonte: Autores (2020)

A ordem para iniciar o jogo fica a critério do orientador ou de forma aleatória. Para avançar às casas, sendo essa a forma de pontuar no jogo, os jogadores terão que escolher ao acaso uma carta-pergunta (Figura 6) que possui um questionamento sobre conteúdos trabalhados nas 
disciplinas de Gestão Empresarial e Estratégia e Gestão de Operações (mencionados da tabela 1) e sua respectiva resposta, logo em seguida o jogador deverá escolher ao acaso uma cartaaposta (figura 7) que possui limites de quantas casas ao máximo o jogador poderá escolher para avançar caso acerte o questionamento da carta pergunta. A carta aposta poderá ser visualizada pelo jogador logo após sua escolha, a carta pergunta deverá ser visualizada e lida somente pelo aplicador.

Figura 6- Carta-pergunta

Carta-pergunta

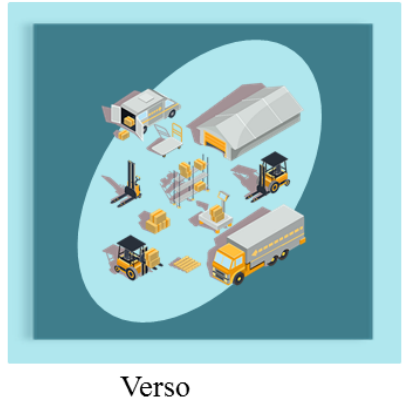

Verso

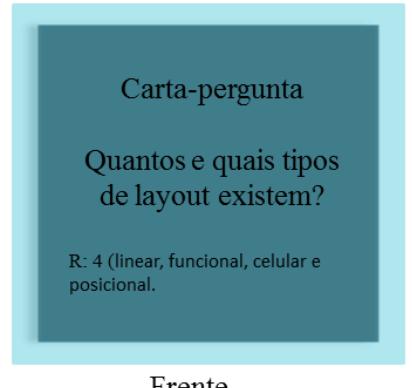

Frente

Fonte: Autores (2020)

Figura 7- Carta-aposta

Carta-aposta

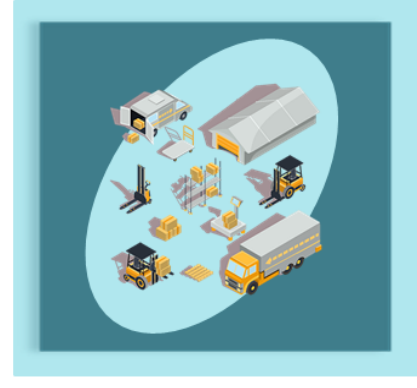

Verso

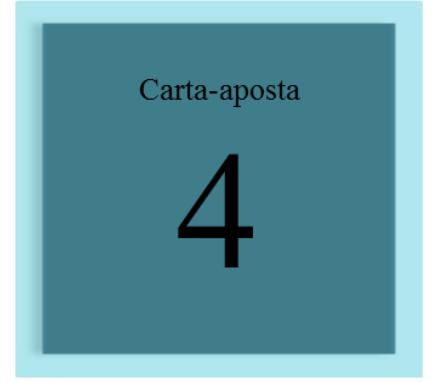

Frente

Fonte: Autores (2020)

Com a carta aposta em mãos, o jogador pode optar por escolher seu limite antes ou depois de responder o questionamento da carta pergunta, a escolha não poderá ser alterada. Após o aplicador ler o questionamento, o jogador terá o tempo de $1 \mathrm{~min}$ para responder, caso acerte, o 
jogador moverá seu dado avatar para a casa determinada considerando a escolha do limite (nessa perspectiva a carta será retirada do jogo), caso erre, o jogador deverá regressar a quantidade de casas também considerando a escolha do limite (nessa perspectiva a carta retornará para a possibilidade de escolha dos outros jogadores), exceto na primeira jogada pois o jogo não possui saldo negativo, caso o tempo seja esgotado o jogador poderá optar pelo repasse para o próximo jogador considerando o mesmo limite escolhido ou pelo retorno da carta pergunta ao jogo. As penalidades estão presentes em algumas das casas ilustrado em destaque pela Figura 8, ganha o jogo o grupo ou jogador que chegar a última casa no menor tempo.

Figura 8- Penalidades

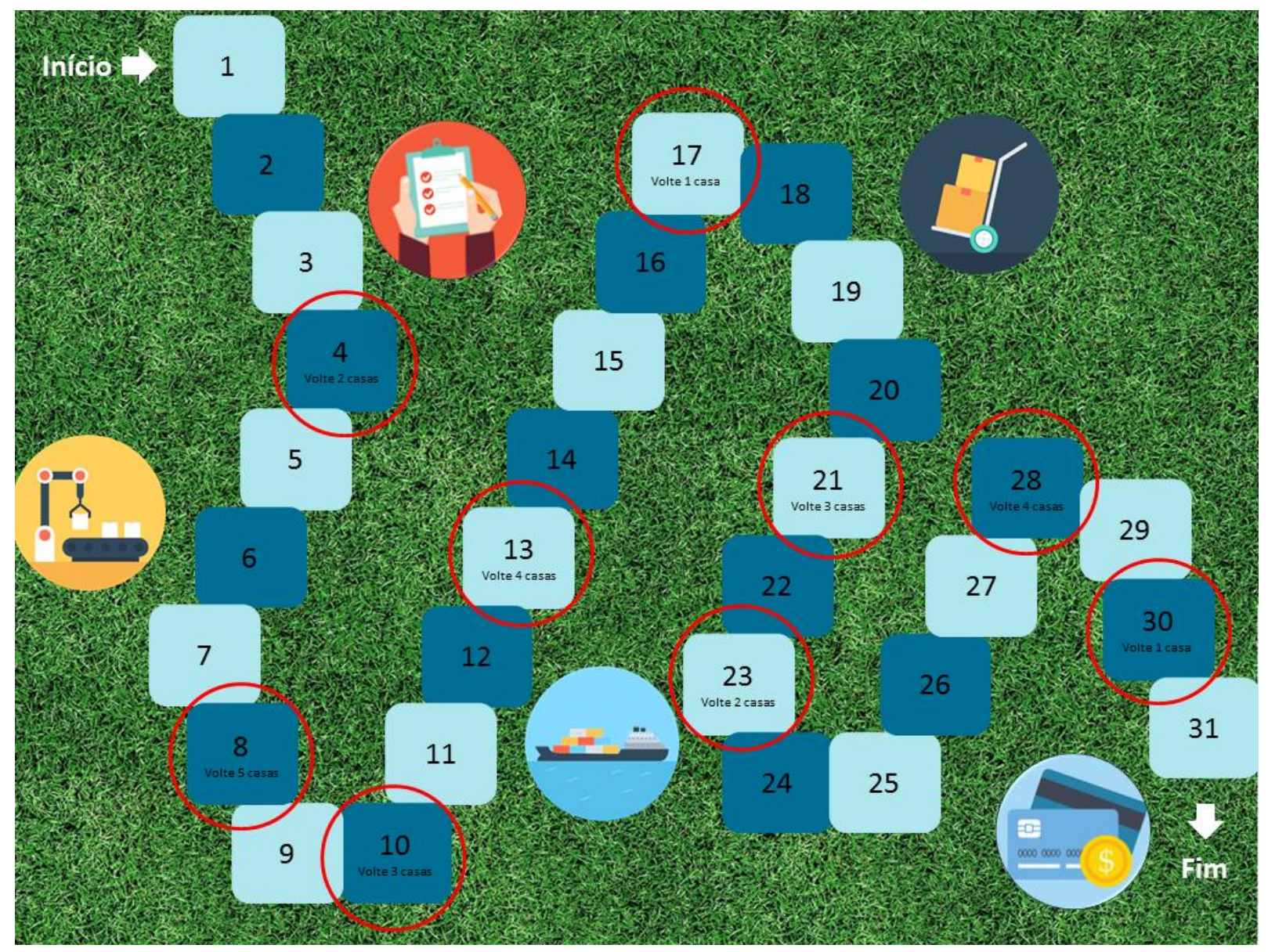

Fonte: Autores (2020)

\subsection{Prática}


Para a prática do jogo Learning Management 1.0, devem estar disponíveis a cada grupo de quatro componentes - capacidade máxima por grupo-:

- 1 Tabuleiro

- 40 Cartas-pergunta

- 40 Cartas-aposta (variam do limite 1 ao limite 4)

- 4 Dados avatar

O vencedor do jogo será aquele que chegar ao final do tabuleiro primeiro.

\section{Conclusão}

O desenvolvimento do jogo Learning Management 1.0 cumpriu com o seu objetivo de somar métodos didáticos e eficazes no ensino da logística. Aplicando-o como forma auxiliar e não exclusiva de educação, há de se perceber as vantagens citadas durante a construção desse artigo quanto à prática de jogos no contexto educacional.

Essa junção dos jogos com a educação torna-se estratégica, visto a carência de ferramentas desse eixo que sejam coerentes com a atual tecnocracia competitiva arquitetada pelo mercado.

Sendo assim, a elaboração desse jogo contribui para a expansão de um conjunto limitado de elementos dinâmicos e didáticos aplicados a educação das práticas logísticos, ainda em processo de aderência no mercado.

\section{REFERÊNCIAS}

BALLOU, R. H. Business logistics management. Englewood Cliffs, NJ: Prentice Hallm, 1999.

BARBOSA, Laura Monte Serrat. Projeto de trabalho: uma forma de atuação psicopedagógica. 2.ed. Curitiba: L. M.S, 1998.

BARBOSA, Laura Monte Serrat. Projeto de trabalho: uma forma de atuação psicopedagógica. 2.ed. Curitiba: L. M.S, 1998.

CARLSON, John GH; MISSHAUK, Michael J. Introduction to gaming: management decision simulations. 1972.

FERNANDES, Isac Gabriel Martins et al. Planejamento estratégico: análise SWOT. Revista Conexão Eletrônica das Faculdades Integradas de Três Lagoas, Mato Grosso do Sul, v. 8, n. 01, 2015. 
HONAISER, Eduardo Henrique Rangel; SAUAIA, Antonio Carlos Aidar. Desenvolvimento e Aplicação de urn Modelo para Previsão de Demanda em jogos de Empresas. RAC-Eletrônica, v. 2, n. 3, 2008.

KAPLAN, Robert S.; NORTON, David P. A estratégia em ação: balanced scorecard. Gulf Professional Publishing, 1997.

KAPP, Karl M. The gamification of learning and instruction: game-based methods and strategies for training and education. San Francisco: Pfeiffer, 2012.

LAUGENI, Fernando P.; MARTINS, Petrônio G. 3. Ed. - São Paulo: Saraiva, 2015. Logística empresarial. $4^{\text {a }}$ ed. Porto Alegre: Bookmann, 2001.

LISBOA, João Veríssimo; GOMES, Carlos Ferreira. Gestão de operações. Vida Económica, p. 159-256, 2006.

MAIA, Tatiane Silva Tavares. Estudos de caso de práticas de gestão de operações em empresas familiares. Revista Gestão da Produção Operações e Sistemas, n. 2, p. 137, 2008.

MARTINELLI, D. A utilização dos Jogos de Empresas no ensino de Administração. Dissertação (Mestrado em Administração) - Programa de Pós-graduação em Administração.

MIYASHITA, R. Elaboração e uso de um jogo de Logística. Dissertação (Mestrado em Administração) Instituto de Pós-Graduação e Pesquisa em Administração, UFRJ/COPPEAD, Rio de Janeiro, 1997.

MIYASHITA, Ricardo; OLIVEIRA, LFVS de M.; YOSHIZAKI, H. T. Y. Os jogos de empresas como instrumento de treinamento em logística empresarial. In: Simpósio de Engenharia de Produção. 2003. p. 1-10.

NICOLAU, Isabel. O conceito de estratégia. INDEG/ISCTE, p. 637-658, 2001

SAUAIA, Antonio Carlos Aidar. Laboratório de gestão: simulador organizacional, jogo de empresas e pesquisa aplicada. Editora Manole, 2008.

SILVA, G. M. S, PEDROSA, M. E. C.; SÁ, A. B. P. O.;.; ASSUNÇÃO, M. V. D. PLAYING WITH 80-20: UMA PROPOSTA LÚDICA PARA O EXERCÍCIO DA CLASSIFICAÇÃO ABC. II Simpósio Nacional de Engenharia de Produção. Dourados/ MS 2019.

TAROUCO, Liane Margarida Rockenbach et al. Jogos educacionais. RENOTE: revista novas tecnologias na educação [recurso eletrônico]. Porto Alegre, RS, 2004.

TORTORELLA, Guilherme L.; FOGLIATTO, Flávio S. Planejamento sistemático de layout com apoio de análise de decisão multicritério. Production, v. 18, n. 3, p. 609-624, 2008.

URBAN, T. L. Combining Qualitative and Quantitative Analyses in Facility Layout. Production and Inventory Management Journal, n. 3/4, p. 73, 1989.

VIEIRA FILHO, L.; MATOS, F.; GUEDES, M.; DINIZ, G.; DINIZ Jr., A. Jogo de Empresas: Caracterização e Implementação Computacional de um Modelo para o Ensino da Logística - GILOG. In: ENCONTRO DA 
ASSOCIAÇÃO NACIONAL DE PÓS GRADUAÇÃO E PESQUISA EM ADMINISTRAÇÃO, 32., 2008, Rio de Janeiro. Anais... Rio de Janeiro: ANPAD, 2008.

WILHELM, P. P. H. Uma Nova Perspectiva de Aproveitamento e Uso dos Jogos de Empresas. 1997. Tese (Doutorado em Engenharia de Produção) - Universidade Federal de Santa Catarina, Florianópolis, 1997. 